CYBERNETICS AND INFORMATION TECHNOLOGIES • Volume 15, No 6 Special Issue on Logistics, Informatics and Service Science

Sofia $\bullet 2015$

\title{
Knowledge Model Based on Graphical Semantic Perception
}

\section{Liu Jian, Huang Haisong, Pan Weijie}

Key Laboratory of Advanced Manufacturing Technology, Ministry of Education, Guizhou University, Guiyang, Guizhou, 550003 China

Emails:1305515940@qq.com_1046534381@qq.com_290008933@qq.com

\begin{abstract}
Based on knowledge representation in product design, we propose a knowledge model of the product design process based on graphical semantic perception. The ontology semantic of the product is analyzed together with the product design process knowledge. Then the basic element model for knowledge representation of the product design process is built. With the concepts of the extension origin point basic element and extension vector thus defined, knowledge representation, consisting of growth, convergence and optimization is realized. On this basis, the model for case base clustering based on graphical semantics is built. Feasibility verification is performed with the case of appearance design of a machine tool. The highlight of the proposed method lies in the combination of the formalized and quantitative approach for product appearance design.
\end{abstract}

Keywords: Graphical semantic; extenics; graphical semantic primitives; appearance design; case reasoning.

\section{Introduction}

At present product innovation methods, relying on the product case base, knowledge representation, knowledge mining and reuse, seem to dominate the design of industrial products. Particularly, knowledge modelling, representation, retrieval, extraction and reuse in the field of industrial product appearance design attract greater attention. 
O man et al. [1] from Oregon State University proposed a methodology for rapid product design using innovation knowledge base, which described the whole process of the information transfer and deduction involved in conceptual product design. L e e, Gu and W illi a m s. [2] from Newcastle University were concerned with the combination of the parametric design and conceptual design and came up with an individualized conceptual design method that can be parameterized. Le e [3] from the National University of Kaohsiung studied the local culture elements and the design of cultural creative products from the extenics perspective. A 1Sayed, Dalton and Hölscher [4] from the University College of London were mainly devoted to the topic of externalization of tacit knowledge in conceptual architectural design. The Indian scholars $\mathrm{Soni}, \mathrm{Khanna}$ and Tandon [5] developed a knowledge-based aesthetic support system for industrial products. L u o et al. [6] and $\mathrm{Luo}, \mathrm{Pan}$ and $\mathrm{Zhu}$ [7] from Zhejiang University advanced the theory of graphical thinking. $\mathrm{Zhu}$ and $\mathrm{Lu} o$ [8] established a method for cultural relics element reconstruction based on design semiotics. Liu, Lu and Sun [9], Liu, Sun and Lu [10], Zheng and Pan [11], Liu and Sun [12] made a research on the method for acquisition of the production innovation knowledge based on a knowledge flow. They proposed the product appearance classification oriented towards design knowledge reuse and the construction of an industrial design knowledge map oriented towards the process. Gu o et al. [13] developed a large-scale 3D monster design and modelling system based on the model base and rule configuration. Liu et al. [14], Li iu and $\mathrm{Xue} \mathrm{[15]} \mathrm{from} \mathrm{Southeast} \mathrm{University}$ employed the basic element theory in extenics and built the basic element model specialized for the conceptual design stage. T ang [16] from Donghua University introduced the concepts of morphology domain and modulized features into product conformational analysis and design. $\mathrm{Y} \mathrm{ang}, \mathrm{Yu}$ and $\mathrm{Chu}$ [17] from Northwestern Polytechnical University combined TRIZ with extension methods in innovative product design, thus proposing an approach for innovative product design based on extension model.

Appearance characteristic semantic is crucial for knowledge representation of mechanical equipment. The appearance design of mechanical equipment is a process where disordered human inspiration interacts with the rigorous design knowledge-based inference and reuse. Therefore, an efficient route of mechanical product appearance design consists of mining product characteristic semantic, analyzing ways of knowledge reuse and objective semantic representation, and reasoning. Starting from users' individualized demand, we propose a method of mechanical product appearance design based on graphical semantic perception. With findings from the research of design process knowledge model, the characteristic semantic and latent semantic related to the product is mined in the product case base. Thus the extension cluster mapping set based on graphical semantic of the products is built. Furthermore, the design rules of a real case are mined, and the design rule database based on Case-Based Reasoning (CBR) is established. Finally, the appearance design scenario driven by the graphical semantic clustering and design rule is created for realization of the product appearance design based on CBR. 


\section{Knowledge analysis and representation during product design process}

\subsection{Knowledge transfer mechanism of product design process}

Design knowledge includes users' demand knowledge, produce design process knowledge and manufacture knowledge. With products serving as the carrier, the knowledge is acquired, transferred and evolved via the agents of users, designers and manufacturers (Fig. 1).

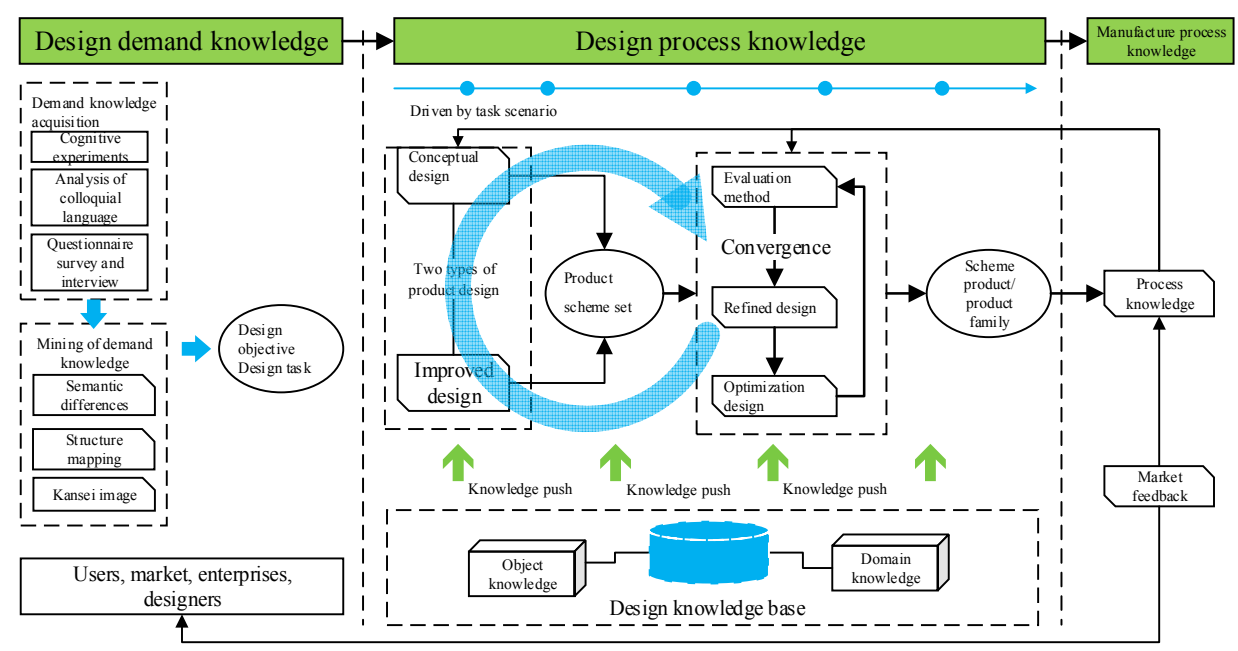

Fig. 1. Knowledge transfer model of the product design process

\subsection{Basic element representation of the design knowledge}

We seek for a new pathway of product design by drawing on the knowledge transfer model and combining the basic element theory, extension innovation method and graphical thinking together. The method of extension representation based on graphical semantic perception is proposed.

The concept of basic element unites the characteristics of quantity, actions and relations under a triplet consisting of an object $O$, characteristic $C$ and value $V$, which is a formalization of objects, affairs and relations. The basic element $B$ is divided into a matter element $M$, an affair element $A$ and a relation element $R$.

The basic element is expressed as

$$
B=(O, \quad C, \quad V)=\left[\begin{array}{ccc}
O & c_{1} & v_{1} \\
& c_{2} & v_{2} \\
\cdots & \ldots \\
& c_{n} & v_{n}
\end{array}\right] .
$$


The basic element of the conceptual design $S=\{B\}$ is constructed for quantitative and qualitative representation of the design process. Hence the method of innovative product design is described intuitively.

\subsection{Connotation analysis of the extension innovation of the design process}

From the perspective of extension innovation, the product design is divided into three stages: concept growth stage, convergence stage and refined design. These three stages are related with each other either through single-level cycling or multilevel cycling, as embodied by a rhombus through model (Fig. 2).

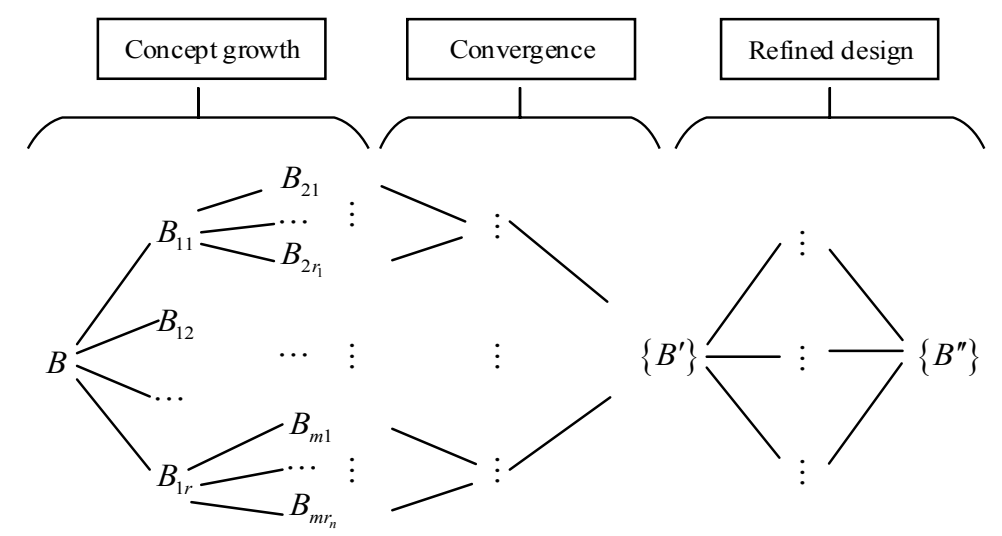

Fig. 2. Rhombus thought models in design process

1) Concept growth stage: Depending on the extendibility or conjugation of the basic elements [18], the innovative thinking process $T$ can be divided into extension analysis, conjugated analysis and extension transformation, collectively represented as $B-\left\{B_{1}, B_{2}, \ldots, B_{n}\right\}$. The basic element set of the product concepts is thus formed as $S=\{B\}$, which fully embodies the extension thinking model of "several characteristics corresponding to one object", "several values corresponding to one characteristic" and "several characteristics corresponding to one value".

2) Convergence stage: The basic element set of the product concepts is converged through the implementation of an evaluation model. The basic element set after convergence is $S^{\prime}=\left\{B^{\prime}\right\}$, expressed as $\left\{B_{1}, B_{2}, \ldots, B_{n}\right\} \vdash\left\{B_{1}^{\prime}, B_{2}^{\prime}, \ldots, B_{m}^{\prime}\right\}$, where $n \geq m$.

3) Refined design stage: Refined design and optimization design are thus possible with a basic element set $S^{\prime}=\left\{B^{\prime}\right\}$. The conflict and incompatibility during the translation of the concepts into products are resolved through conjugated analysis and extension transformation. Hence, the product or product family $S^{\prime \prime}=\left\{B^{\prime \prime}\right\}$ is obtained.

\subsection{Extension representation of design process knowledge}

As discussed above, the extension representation of the design process knowledge is realized as shown in Fig. 3. 


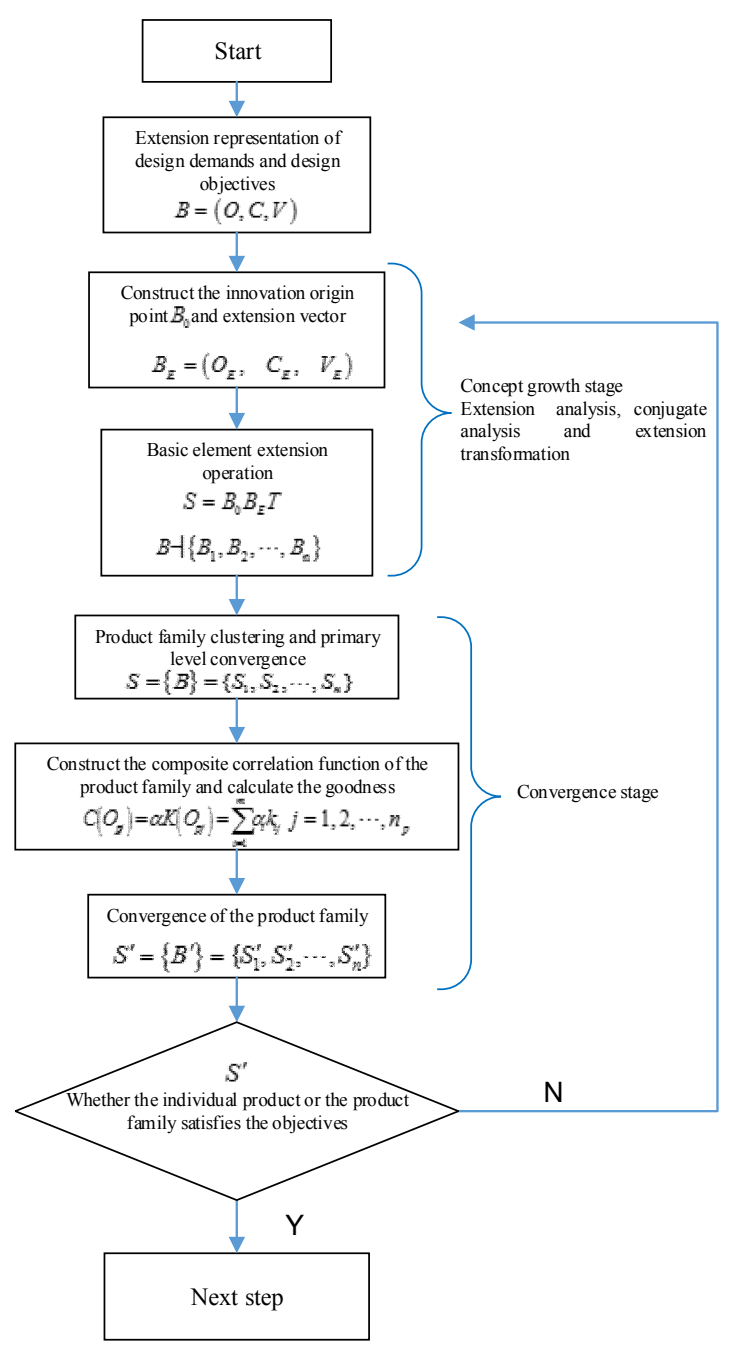

Fig. 3. Extension representation of the product design process knowledge

\section{Knowledge extension method during the concept growth stage}

\subsection{Extension vector}

The basic element of the extension origin point is considered the origin point of product design. $B_{0}$ is defined as the basic element of the extension origin point and $B_{E}$ is the extension vector, with extension direction, extension step length and extension depth falling within the scope of connotation.

$$
B_{E}=\left(O_{E}, \quad C_{E}, V_{E}\right)=\left[\begin{array}{ccc}
O_{E} & \text { Extension directionc }_{\mathrm{Edi}} & v_{\mathrm{Edi}} \\
& \text { Extension step lengthc }_{\mathrm{Ele}} & v_{\mathrm{Ele}} \\
& \text { Extension depthc }_{\mathrm{Ede}} & v_{\mathrm{Ede}}
\end{array}\right],
$$


where the extension direction $c_{\text {Edi }}$ indicates 1 or several design directions, expressed as $c_{\mathrm{Edi}}=\left(c_{\mathrm{Edi}}, c_{\mathrm{Edi} 2}, \ldots, c_{\mathrm{Edi} i}\right)$, and the corresponding value is $v_{\mathrm{Edi}}$;

The extension step length $v_{\text {Ele }}$ can be either a value of step length or the interval of step length, with the expression of $v_{\text {Ele }}=\left\langle l_{\min }, l_{\max }\right\rangle$.

The extension depth $v_{\text {Ede }}$ indicates the number of concept growth $m$, with the expression of $v_{\text {Ede }}=(1,2, \ldots, m)$.

Definition. The extension vector $B_{E}$ describes the concept growth process characterized by the extension direction $c_{\text {Edi }}$, the extension step length $c_{\text {Ele }}$ and the extension depth $c_{\text {Ede }}$ starting from the origin point $B_{0}$.

For specific design problems, concrete meanings are assigned to extension direction $c_{\text {Edi, }}$, extension step length $c_{\text {Ele }}$ and extension depth $c_{\text {Ede }}$.

\subsection{Extension description of the concept growth process}

Considered from the perspective of design methodology combined with extenics, the product design is a process of thought growth starting from the origin point $B_{0}$ and guided by the basic element of the extension vector $B_{E}$. The model of the concept growth stage is presented in Fig. 4. By $S=B_{0} B_{E} T$, and through the extension analysis $B \nmid\left\{B_{1}, B_{2}, \ldots, B_{\mathrm{n}}\right\}$, the basic element set of product schemes $S=\{B\}$ is derived.

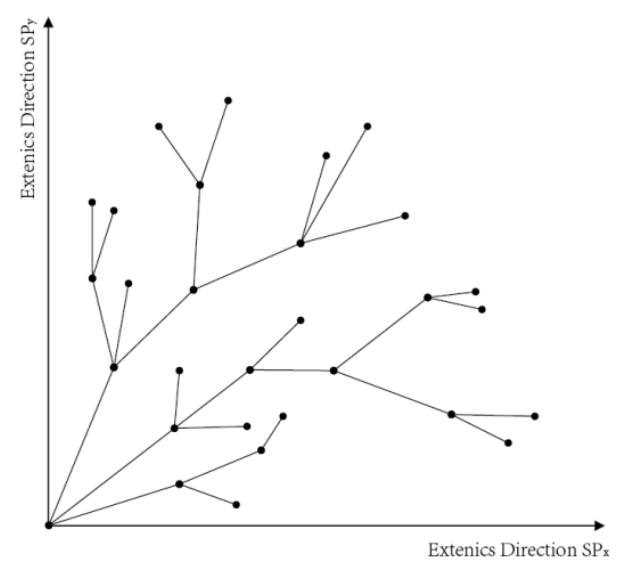

Fig. 4. Product design process

Positive directions $\mathrm{SP}_{x}$ and $\mathrm{SP}_{y}$ of extension design are defined, and $\mathrm{SP}^{+}$as the positive space of the extension design (effective design space). The ensemble of the design objects constitutes the extension domain of design, denoted as $U$. Starting from the basic element of extension origin point, a single level of extension nodes or multiple levels of extension nodes are formed. The node is denoted by $P_{i j}$, where $i$ is the number of the concept growth, $j$ is the count of $i$ growth, and $M$ is the number of nodes, thus we obtain:

$$
M=\sum_{i=1}^{m} \sum_{j=1}^{n_{i}} P_{i j} .
$$


In the extension domain $U$ (Fig. 4), the number of the growth $m$ is the variable. The quantitative expression of the positive space of extension design is $\mathrm{SP}=f(m)$, with $f(m)=m^{2}$. Hence, the density of the extension design is $\rho$, expressed as:

$$
\rho=\frac{M}{\mathrm{SP}}=\frac{\sum_{i=1}^{m} \sum_{j=1}^{n_{i}} P_{i j}}{f(m)}=\frac{\sum_{i=1}^{m} \sum_{j=1}^{n_{i}} P_{i j}}{m^{2}} .
$$

The density of the extension design $\rho$ is a measure of the activity intensity of design thinking in the extension domain $U$ and also an important evaluation indicator of the innovativeness of the product extension set.

\section{Graphical semantic representation of the product}

The combination of the basic element theory and semantics is an efficient route to formalized and quantitative representation of the design process knowledge. However, the semantic representation of the products requires further understanding of the mining of tacit knowledge and the representation for aspecific design case. For instance, in the product appearance design, the descriptive words can be hardly encoded accurately and adequately $[19,20]$ to express the tacit knowledge. To overcome this defect, we introduce graphical semantic perception. The following is an elaboration of the method of appearance design based on graphical semantic perception using the example of a machine tool.

\subsection{Matter element representation of the conceptual design demand}

Based on the analysis of the domain knowledge related to the machine tool, the $4 \mathrm{~S}$ basic element model of product semantic is used to compare the semantic expression and graphical semantic of product (see Table 1)

Table 1. Comparison between semantic expression and graphical semantic

\begin{tabular}{|c|c|c|}
\hline $\begin{array}{c}\text { 4S basic element model } \\
\text { of product semantic }\end{array}$ & Semantic expression & Graphical semantic \\
\hline Semantic primitive & $\begin{array}{c}\text { Centering around the product appearance, } \\
\text { the tacit cultural semantic is conferred to } \\
\text { the product, and the appearance also } \\
\text { facilitates the product usage }\end{array}$ & $\begin{array}{c}\text { Illustration of the } \\
\text { product appearance }\end{array}$ \\
\hline Structure primitive & $\begin{array}{c}\text { Taking the graphics perspective, the } \\
\text { visual contour, symbols, functional rules } \\
\text { and layout are actualized through } \\
\text { appearance design }\end{array}$ & $\begin{array}{c}\text { Illustration of the } \\
\text { contour, symbols }\end{array}$ \\
\hline Context primitive & $\begin{array}{c}\text { Constraints are imposed on the product } \\
\text { style and brand positioning based on user } \\
\text { location }\end{array}$ & $\begin{array}{c}\text { Illustration of the usage } \\
\text { environment, brand } \\
\text { image and stylistic } \\
\text { elements }\end{array}$ \\
\hline Pragmatic primitive & $\begin{array}{c}\text { Knowledge representation is realized of } \\
\text { the user-machine relations based on the } \\
\text { users' thinking habit and semantic } \\
\text { perception }\end{array}$ & $\begin{array}{c}\text { Illustration of user- } \\
\text { machine engineering } \\
\text { constraints }\end{array}$ \\
\hline
\end{tabular}




\subsection{Case base based on graphical semantic clustering}

Case bases are already constructed for lathes, vertical machining center, horizontal machining center and gantry machining center [21]. These bases enable the CaseBased Reasoning (CBR) in product design. We explore the methods of case base representation and retrieval based on graphical semantic [6,7]. By studying the method for clustering and retrieving the case bases, knowledge representation methods that can facilitate knowledge acquisition are proposed.

Graphical semantic basic elements are introduced by combining graphical semantic with basic model theory (Table 2). Thus product case knowledge is represented by means of graphical semantic basic elements and the extension space of graphical semantic. Using these knowledge, the product case base based on graphical semantic is constructed, clustered and then retrieved.

Table 2. Graphical semantic basic element

\begin{tabular}{|c|c|c|c|}
\hline $\begin{array}{c}\text { Element type } \\
\text { Basic element model } \\
\text { in extenics }\end{array}$ & $O$ & $C$ & $V=C(O)$ \\
\hline $\begin{array}{c}\text { Graphical semantic } \\
\text { primitive }\end{array}$ & Graphic & $\begin{array}{c}\text { Graphical } \\
\text { characteristic }\end{array}$ & $\begin{array}{c}\text { Graphical characteristic } \\
\text { value }\end{array}$ \\
\hline
\end{tabular}

Unlike the conventional basic element theory, $O, C, V$ in graphical semantic basic element are all graphical illustrations.

Take MK1080 CNC centerless grinding machine as an example. The formalized expression of graphical semantic in terms of extenics is shown as follows:

$$
B=(O, C, \quad V)=
$$

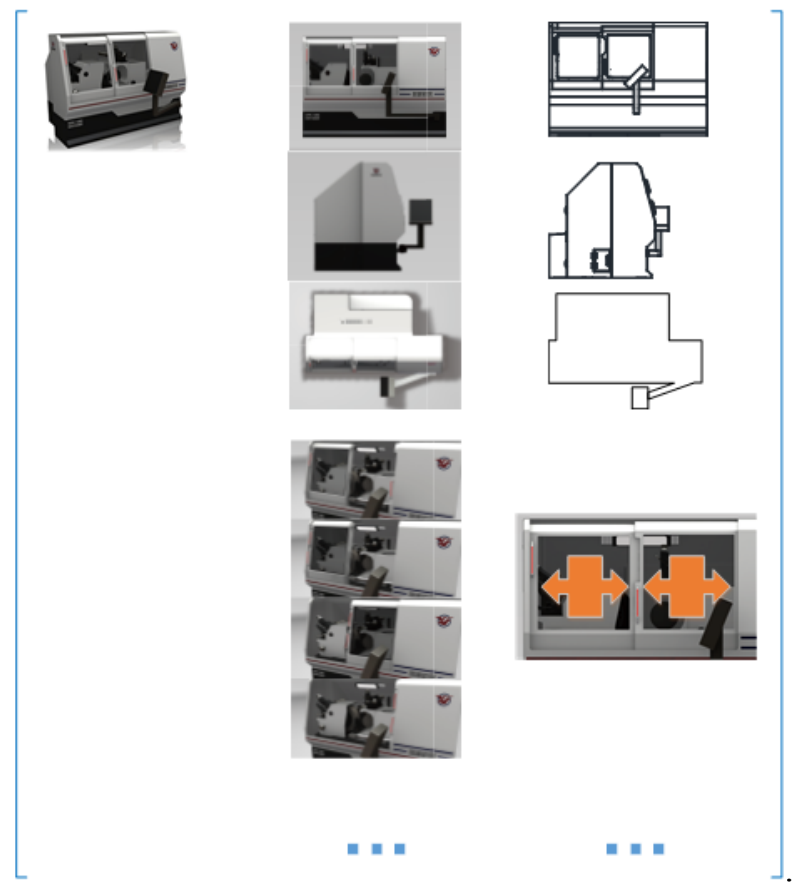




\section{1) Graphical semantic expression of contour}

It is known from the interview with the designers that the most direct way of knowledge acquisition is the acquisition of appearance semantic. The index form based on graphical semantic perception is derived by extracting contour line vectors and similarity computation, thus simplifying the retrieval of target cases by the users (designers or the users of machine tool). Fig. 5 is a comparison of clustering based on graphical semantic and design language.

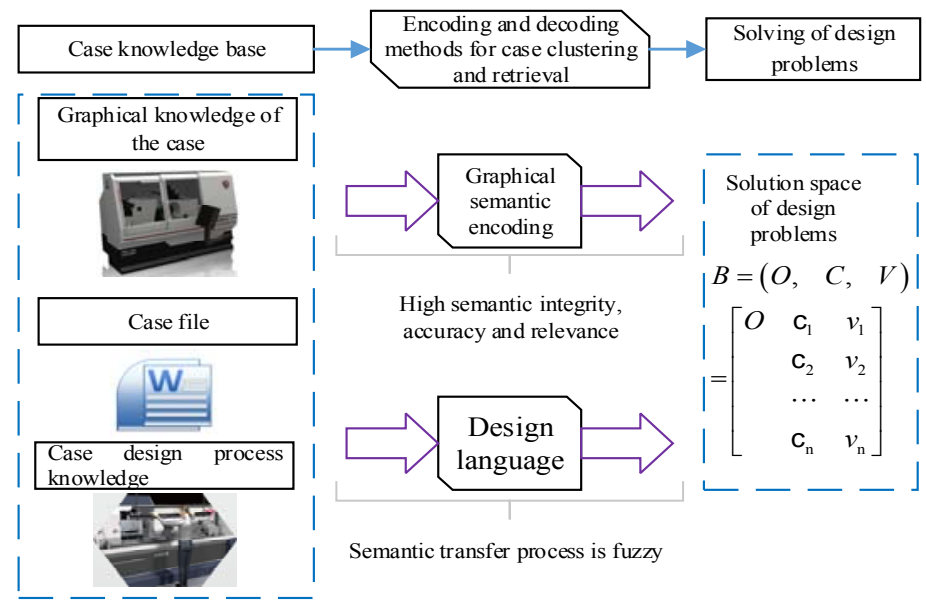

Fig. 5. Product clustering method

The case-based analysis of the machine tool appearance characteristics is performed. The contour lines in the three-view drawing of the appearance have good identifiability and relevance. Take the centerless grinding machine as an example. Centerless grinding machine is divided into 12 major categories with over 150 product cases available. The products belonging to the same series share highly similar appearance characteristics in terms of main body contour. Standardized clustering based on graphical semantic is carried out using the three-view drawing (Fig. 6).

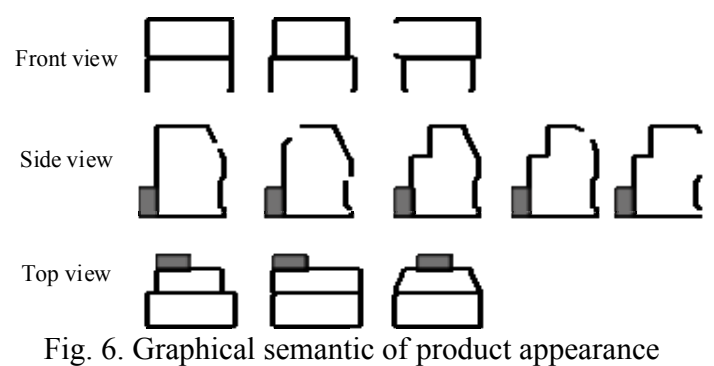

2) Graphical semantic expression of the functional modules

Based on product contour, the functional modules are properly configured. Machine tools usually have a fixed set of appearance functional modules. These modules include protective door (for clamping workpiece and observing), maintenance door 
(maintenance \& repair, observation), machine control module, and auxiliary modules (auxiliary material loading module, such as the loading and recycling of coolant, grinding fluid and lubricants). Fig. 7 is an example of the graphical semantic of the functional module (protective door). The main semantic characteristics of the protective door relate to the amount and usage of the door.

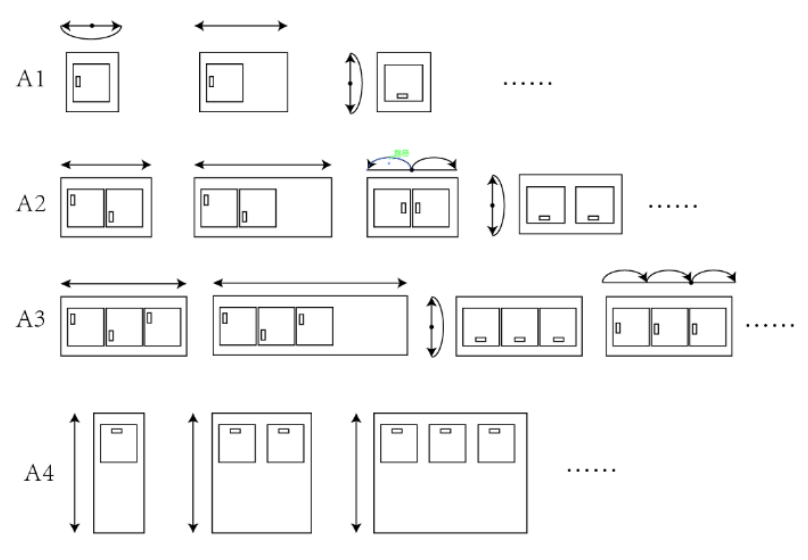

Fig. 7. Graphical semantic of function module

\section{Design case}

The design of MK8420 CNC roll grinding machine is described in details in this section.

1) Determination of design demand and objective characterization

Table 3 shows the design strategy targeting the main design problems of the roll grinding machine.

Table 3. Design strategy
\begin{tabular}{|l|l|}
\hline Main design problems & Solving strategy \\
\hline Overall appearance & Split type design \\
\hline Protective door at the working position & Push and pull on the tracks \\
\hline Overall style & Product seriation \\
\hline
\end{tabular}

2) Design process scenario

The extension vector is constructed according to the design strategy:

$$
=\left[\begin{array}{ccc}
B_{E}=\left(O_{E},\right. & \left.C_{E}, \quad V_{E}\right)= \\
\text { Eppearance design } & \text { Extension direction } & \text { Contour } \\
& \text { Extension step length } & l=1 \\
& \text { Extension depth } & n \geq 2
\end{array}\right] .
$$

The contour is the extension direction, and the extension step length $l=1$ means that the threshold of semantic relevance is 1 . That is to say, the scope of the case retrieval is delineated by the rigorous objective semantic value. $l>1$ indicates the 
extension degree in the case retrieval; the extension depth $n \geq 2$ indicates the reference number of optimal cases. Fig. 8 is the CAD image detailing the specification of the machine tool in the top view.

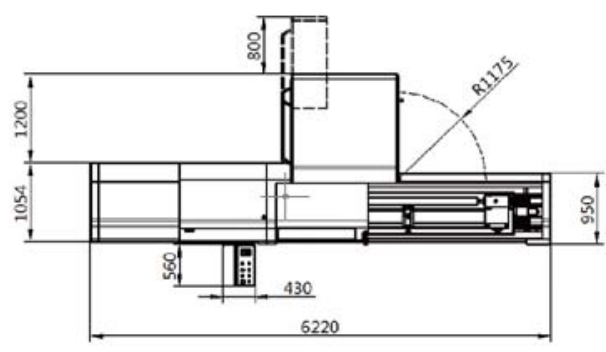

Fig. 8. Top view of grinding machine MK8420

The criterion for appearance graphical semantic clustering is as follows:

$$
C_{\text {ap } 1}=\stackrel{\square}{\longrightarrow} \longrightarrow,
$$

The product cases are retrieved based on set $A=\left\{a_{1}, a_{2}, \ldots, a_{n}\right\}$ (see Fig. 9). The MK8420 grinding machine being designed belongs to MK84 product family and therefore possesses the feature of miniaturized end points. However, its functional layout differs greatly from the products of the same series. A re-design is needed based on the reference case $A=\left\{a_{1}, a_{2}, \ldots, a_{n}\right\}$ with certain revisions. Here case $a_{7}, a_{10}$ is chosen as a reference for the appearance design scheme.

The case retrieval is done by the functional module of the protective door. Man-machine interactions are constrained by the functions of workpiece hoisting and clamping from the man-machine engineering perspective. The operation protection is implemented in a semi-closed manner. The single sliding door is selected, and the retrieval type is

$$
C_{\mathrm{mo} 2}=\overleftrightarrow{\square},
$$

The basic element set $B=\left\{b_{1}, b_{2}, \ldots, b_{n}\right\}$ of the product cases is retrieved as shown in Fig. 9. $b_{4}, b_{10}, b_{11}$ are taken as cases of a protective door.

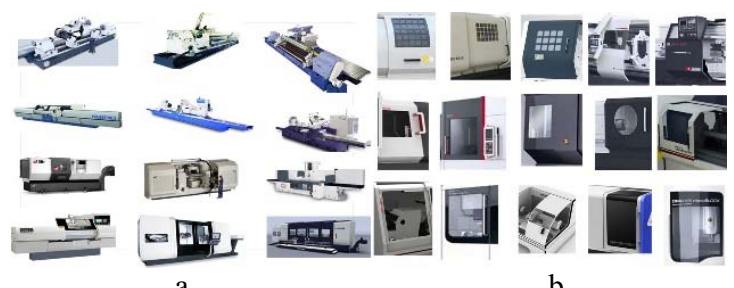

Fig. 9. Product appearance case and basic element set of a protective door appearance case

Based on the cases of overall appearance and main functional modules, the preliminary schemes of appearance are formulated. This is followed by manmachine engineering analysis to achieve extension transformation and conjugated analysis. The final rendering is shown in Fig. 10. 


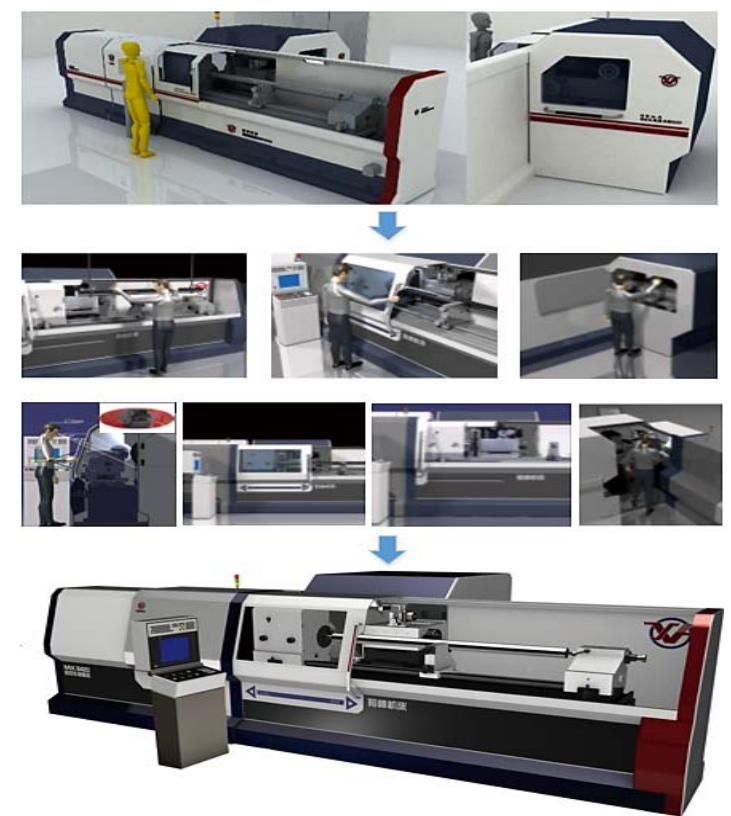

Fig. 10. Final rendering

\section{Conclusion}

We propose the concepts of extension origin point basic element and extension vector by combining product ontology semantic with design information processing model of human brain. Moreover, the knowledge representation model is built based on basic element theory in extenics. In this way, the knowledge of concept growth, convergence and optimization during the design process is represented. Using this model, the method of case base clustering based on graphical semantic is presented. The semantic graphical representation of the case base and scenariobased representation of CBR are realized for machine tool appearance design taken as an example. The proposed method is a combination of formulization and quantification. However, the case retrieval method based on graphical contours is not discussed in the present study. Future directions of study include (1) method of graphical semantic retrieval and convergence; (2) computer-based recognition of graphical semantic; (3) applications of extension operation in appearance design.

\section{References}

1. O m a n, S., B. Gil c hri s t, I. Y. T u m e r et al. The Development of a Repository of Innovative Products (RIP) for Inspiration in Engineering Design. - International Journal of Design Creativity and Innovation, Vol. 2, 2014, No 4, pp. 186-202.

2. L e e, J., N. G u, A. P. W i 11 i a m s. Parametric Design Strategies for the Generation of Creative Designs. - International Journal of Architectural Computing, Vol. 12, 2014, No 3, pp. 263-282. 
3. L e e, Y. Exploration of Local Culture Elements and Design of Cultural Creativity Products. Journal of Statistics and Management Systems, Vol. 13, 2010, No 4, pp. 775-788.

4. A l-S a y ed, K., R. C. Dalto n, C. Höls cher. Discursive Design Thinking: The Role of Explicit Knowledge in Creative Architectural Design Reasoning. - Artificial Intelligence for Engineering Design, Analysis and Manufacturing, Vol. 24, 2010, No 2, pp. 211-230.

5. Soni, S., P. Khanna, P. Tandon. Knowledge Support System for Aesthetics in Product Design. - Journal of Computing and Information Science in Engineering, Vol. 13, 2013, No 1, p. 11006.

6. L u o, S., S. Z h u, F. Y in g et al. Statues and Progress of Research on Users' Tacit Knowledge in Product Design. - Computer Integrated Manufacturing Systems, Vol. 16, 2010, No 4, pp. 673-688.

7. L u o, S., Y. P a n, S. Zhu. Patterns of Tacit Knowledge Based on Graphic Thinking in Product Design. -Journal of Mechanical Engineering, Vol. 43, 2007, No 6, pp. 93-98.

8. Z hu, S., S. Lu o. Reproduction of Cultural Relics Elements Based on Design Semiotics in Product Design. - Journal of Zhejiang University (Engineering Edition), Vol. 47, 2013, No 11, pp. 2065-2072.

9. Li u, Z., N. Lu, L. Sun. Method of Product Innovation Knowledge Acquisition Based on Knowledge Flow. - Computer Integrated Manufacturing Systems, Vol. 17, 2011, No 1, pp. 10-17.

10. L i u, Z., L. S u n, N. L u. Construction of Process-Oriented Industrial Design Knowledge Map. Journal of Mechanical Engineering, Vol. 46, 2010, No 8, pp. 181-187.

11. Zheng, S. S., Y. P a n. A Reuse-Oriented Knowledge Classification and Representation for Product Design Process. - Journal of Mechanical Engineering, Vol. 45, 2009, No 4, pp. 19-24.

12. L i u, Z., S. S u n. A Knowledge Management System for Product Form Design. - Journal of Computer-Aided Design \& Computer Graphics, Vol. 21, 2009, No 3, pp. 376-381.

13. Gu o, X., J. Li n, K. X u et al. Creature Grammar for Creative Modeling of 3D Monsters. Graphical Models, Vol. 76, 2014, No 5, pp. 376-389.

14. L i u, L., C. X u e, J. L i et al. Characterization and Reconstruction of Product Using-Way Based on Basic Element Model. - Journal of Graphics, Vol. 34, 2013, No 03, pp. 90-94.

15. L i u, L., C. Xu e. Creative Design Methods and Characterization Based on Rhombus thought Models. - Packaging Engineering, Vol. 34, 2013, No 10, pp. 7-9.

16. Tang, Z. Research on Product Conformational Analysis and Design Based on Morphology Domain and Modularized Characteristics. Donghua University, 2014.

17. Y a n g, G., S. Y u, J. C h u. A New Product Innovation Design Method Based on Extenics Model. - Packaging Engineering, Vol. 32, 2011, No 18, pp. 30-33.

18. Y a n g, C., W. C a i. Extenics. Beijing, Science Press, 2014, pp. 37-55.

19. G a o, L. Product Semantic Design. Beijing, China Machine Press, 2014. 77 p.

20. D a i, R. Product Form Design Semantic and Communication. Higher Education Press, 2010, pp. 67-69.

21. Z h a n g, J. Research and Application of Knowledge-Based Complex Product Industrial Design Assisted System. Hunan University, 2013. 